\title{
Maximizing the Functional Performance Outcomes of Patients Undergoing Rehabilitation by Maximizing their Overall Health and Wellbeing
}

\author{
by \\ Elizabeth Dean ${ }^{1}$
}

To maximize the performance of an athlete, a team of experts work together to ensure each athlete achieves the maximal benefit from their prescribed exercise conditioning programs. In addition to the exercise specialists, the athlete's team frequently includes psychologists (who address performance anxiety, stress, and depression), counselors (who address smoking cessation, reduction or elimination of alcohol consumption if necessary, weight optimization, and optimal sleep), and nutritionists (who address optimal nutrition and body mass attributes). Such a collaborative approach has become standard practice for athletes aiming to excel in their sports. Despite unequivocal and compelling evidence, this paradigm has only weakly been transferred to the needs of patients participating in rehabilitation programs. These individuals, like the athlete, also need to achieve their highest level of functional performance and recovery for carrying out their activities of daily living, managing the needs of their families, and often returning to work. This article reviews the evidence-based literature and the implications of this multifaceted approach in rehabilitation programs. The augmented benefits to exercise training and conditioning (prescriptive activity/exercise and less sitting) along with their 'effect sizes' are described in the rehabilitation context, in conjunction with smoking cessation, reduced harmful alcohol consumption, optimal nutrition, optimal body mass, manageable stress, and optimal sleep. These factors can be viewed as physical performance enhancers both in individuals participating in rehabilitation whose aim is maximal performance and recovery and in athletes aiming for maximal performance in their sports. Thus, without targeted attention to these lifestyle factors, rehabilitation outcomes cannot be maximized. The evidence presented in this article has implications for health professionals including physical therapists and others who are practicing in rehabilitation settings and those working with individuals in need in the community.

Key words: athletes, healthy lifestyle practices, physical performance, International Classification of Function, Disability and Health, Behavioral Risk Factor Surveillance System.

\section{Introduction}

To maximize the performance of an athlete, a team of experts work together to ensure each athlete achieves the maximal benefit from their prescribed exercise training programs. In addition to the exercise specialists, the athlete's support team frequently includes psychologists (who address performance anxiety, stress, and depression), counselors (who address smoking cessation, reduction or elimination of alcohol consumption if necessary, weight optimization, and optimal sleep), and nutritionists (who address optimal nutrition and body mass composition and attributes) (McArdle et al., 2015; Prentice, 2016). Such a collaborative approach has become standard practice for athletes aiming to excel in their sports irrespective of the level (physical activity and sports programs for school children and youth, university athletics, amateur sport, as well as high level competition such as the Olympic Games).

Despite unequivocal and compelling evidence, this overall health-focused paradigm

1 - Department of Physical Therapy, Faculty of Medicine, University of British Columbia, Vancouver, Canada. 
has only weakly been transferred to the needs of patients participating in rehabilitation programs. Comparable to athletes, these individuals also need to achieve their highest level of functional performance, capacity, and recovery for carrying out their activities of daily living, returning to or continuing to be employed, and managing the needs of their families. This is well exemplified in the patient management framework endorsed by the World Health Organization, in turn, the World Confederation for Physical Therapy, namely the International Classification of Function, Disability and Health (ICF) (Figure 1) (World Health Organization, 2001). Figure 1 shows the ICF and depicts the key role of environment and personal factors including lifestyle factors on body function and structure, activity and social participation. In rehabilitation, lifestyle factors are becoming increasingly the focus of attention. Initially, the priority was to prevent, reverse or management of lifestylerelated non-communicable diseases (NCDs) (e.g., ischemic heart disease, cancer, hypertension, stroke, type 2 diabetes mellitus, and chronic obstructive lung disease). Risk factors include smoking, poor diet, overweight/obesity, sedentary behavior, inactivity and lack of exercise, poor sleep, as well as anxiety and depression. In recent years, however, these classic risk factors for lifestyle-related NCDs have been shown to be associated with musculoskeletal conditions, commonly seen by rehabilitation specialists such as physical therapists (Dean and Söderlund, 2015; Shiri et al., 2006). Thus, musculoskeletal conditions may be prevented, reversed, and respond more quickly and favorably to rehabilitation, medication and surgery, if patients practice healthy lifestyles.

The Behavioral Risk Factor Surveillance System (BRFSS) has provided a basis for establishing the health status and health risks of people with disabilities compared with those without such disability (Ahluwalia et al., 2003; Tsai et al. 2010). People with disabilities are $4 \frac{1}{2}$ times more likely to report poor health than those without disabilities. Further, people with disabilities are $50 \%$ more likely to smoke, be obese, and be inactive than those without disabilities. To address this, The Surgeon General's Call to Action to Improve the Health and Wellness of Persons with Disabilities (2005) strongly advocates the importance of not smoking, moderate if any alcohol consumption, healthy eating, maintaining a healthy body mass, being regularly physically active as much as possible. The report concludes that with good health practices as well as appropriate health services, much disability can be prevented or reduced. This conclusion is supported by data from the Behavioral Risk Factor Surveillance System, 2003, reported by McGuire and colleagues (2007). They advocated that older adults with or without disabilities needed to be screened and counselled about healthy lifestyles, thereby reducing the rates of morbidity and premature mortality related to chronic conditions.

Although intervention effect size is a primary focus of biomedical studies, the so-called effect size of simply healthy lifestyle practices is often overlooked or not appreciated. Related to this point, Ford and colleagues (2009) reported on 'healthy living being the best revenge'. In a cohort of over 23,000 adults, they indicated that those with healthier lifestyle behaviors and related attributes (i.e., not smoking, healthy eating practices, optimal body mass, and regular physical activity), for a mean of 7.8 years, the participants' risk for several leading NCDs was dramatically lower. Specifically, the risk for type 2 diabetes mellitus was reduced by $93 \%$, myocardial infarction by $81 \%$, stroke by $50 \%$, and some forms of cancer by $36 \%$. Even if not all four lifestyle behaviors or related attributes were present, the risk of developing one or more chronic lifestyle-related NCDs decreased commensurate with an increase in the number of positive lifestyle factors. Despite health knowledge, awareness and improved healthy literacy in western cultures, healthy living is often challenging to practice for many. Thus, a better understanding of the barriers and facilitators to making healthy choices is needed, to maximize health benefits in people living with disabilities as well as those without. Clearly, knowledge and the feared 'wake-up call' (being diagnosed with a lifethreatening condition) are insufficient. Blanchard and colleagues (2008) reported that even with a diagnosis of cancer, the proverbial wake-up call, survivors' lifestyle behaviors were alarmingly poor, i.e., in 9,105 survivors with six diagnostic categories, only 14.8 to $19.1 \%$ adhered to the recommendations of five servings a day of fruit 
and vegetables and 29.6 to $47.3 \%$ adhered to physical activity recommendations. However, 82.6 to $91.6 \%$ were not smoking. Only 5\% met all three general health recommendations. Thus, lifestyle behavior change warrants targeting specifically with inbuilt mechanisms for lifelong sustainability, as having a potentially terminal diagnosis does not appear to constitute sufficient motivation to change lifestyle behavior. On an encouraging note however, these investigators reported that health-related quality of life improved with each additional positive health behavior reported. Buck and Frosini (2012) observed that adverse lifestyle behaviors tended to cluster, which suggests multipronged health behavior change interventions may be warranted. Given the extant literature, the need for lifestyle behavior change warrants being systematically evaluated along with a targeted intervention planned, in order to continuously and seamlessly support healthy lifestyles in people with or without disabilities.

Rimmer and colleagues (2014) recently described GRAIDs, a framework for closing the gap in the availability of health promotion programs for people with disabilities. The elements of GRAIDs can and should be integrated into traditional rehabilitation programs, so that the effect of improved health can be exploited to maximize conventional rehabilitation outcomes and in the interest of supporting life-long health in this vulnerable population.

Only recently has inter-professional practice been operationalized into the management of non-communicable diseases. Klein and colleagues (2017) described the CHANGE program which is a primary care program involving nutritionists and kinesiologists in the management of metabolic syndrome. The description of this program suggests a potentially powerful and effective means of addressing metabolic syndrome, its risk factors and dire consequences. Physical therapists would augment this team given their expertise in the management of chronic conditions, multi-morbidity and patients on multiple medications. Important and significant outcomes for physical therapists (the largest and leading established nonpharmacological non-surgical profession in the world) are medication reduction or elimination and/or reduction of the need for surgery or potentially less invasive surgery (Dean, 2009a, b). Thus, the exploitation of evidence-based nonpharmacologic intervention is paramount particularly in this era of lifestyle-related noncommunicable diseases, either as primary presenting diagnoses or secondary diagnoses.

This article reviews the evidence-based literature and the implications of this multifaceted lifestyle-focused approach to the management of patients in rehabilitation programs. The augmented benefits to exercise training and conditioning (prescriptive activity/exercise and less sitting) along with consideration of the effect sizes of lifestyle behavior change on patients' functional capacity are described in the rehabilitation context, in conjunction with smoking cessation, moderate or elimination of alcohol consumption, optimal nutrition, optimal body mass, manageable stress, and optimal sleep. These factors can be viewed as physical performance enhancers both in individuals participating in rehabilitation whose aim is maximal performance and recovery and in athletes aiming for maximal performance in their sports. Thus, without targeted attention to these lifestyle factors, rehabilitation outcomes cannot be maximized. The evidence has implications for health professionals including physical therapists and others who are practicing in rehabilitation settings and those working with individuals in need in the community.

\section{Smoking cessation}

The multisystem effects of smoking even minimally have been well established for several decades (Abate et al., 2013; A clinical practice guideline for treating tobacco use and dependence: 2008 Update; The Health Consequences of Smoking-50 Years of Progress: A Report of the Surgeon General., 2014; Strine et al., 2009). These effects are so well established that in athletic training manuals, reference to smoking cessation is often notably absent. With respect to functional capacity, smoking damages airways and the resulting lung disease, in turn, compromising gas exchange and tissue oxygenation. Nicotine binds the oxygen binding sites with carbon monoxide, such that the carbon monoxide levels of smokers are often twice those of non-smokers. The work of breathing, hence physical functioning, is increased. Nicotine is a potent vasosconstrictor, thus limits tissue 
oxygenation directly which impacts exercise capacity and healing. This may be less apparent in a smoker who has no apparent functional limitation or pathology and whose cardiovascular and pulmonary systems can compensate. However, in a person with a disability, even minimal amounts of smoking can compromise functional capacity and maximal response to a rehabilitation program.

\section{Reduced harmful alcohol consumption}

Harmful alcohol consumption adversely affects multiorgan system function (World Health Organization. Global Status Report on Alcohol and Health, 2014). Like smoking, alcohol consumption may be increased in people with disabilities given functional limitation can affect several factors that underlie quality of life, including the capacity to be employed, the capacity to get to and from work or take care of the family, and mental health. Conversely, harmful levels of alcohol consumption and smoking can worsen these factors. Like smoking, abstinence or moderate alcohol consumption is hardly mentioned in athletic training manuals, given this is so apparent. And, comparable to smoking, harmful alcohol consumption has wellestablished multisystem effects especially when prolonged. Notwithstanding individual metabolic differences, general guidelines is 10 drinks a week for women, with no more than 2 drinks a day most days; and 15 drinks a week for men, with no more than 3 drinks a day most days (Canada's Low Risk Alcohol Drinking Guidelines 2012). To establish whether a person has an alcohol addiction or engages in harmful alcohol consumption, the CAGE questionnaire remains a useful tool to provide an index of alcohol addiction (Ewing, 1984).

Eastern Europe including Poland has some of the highest alcohol consumption rates in the world, hence high levels of alcohol-related diseases and disability (Hess et al., 2014; Świątkiewicz et al., 2004). Consideration needs to be given by health and fitness professionals to effectively address this serious cultural issue.

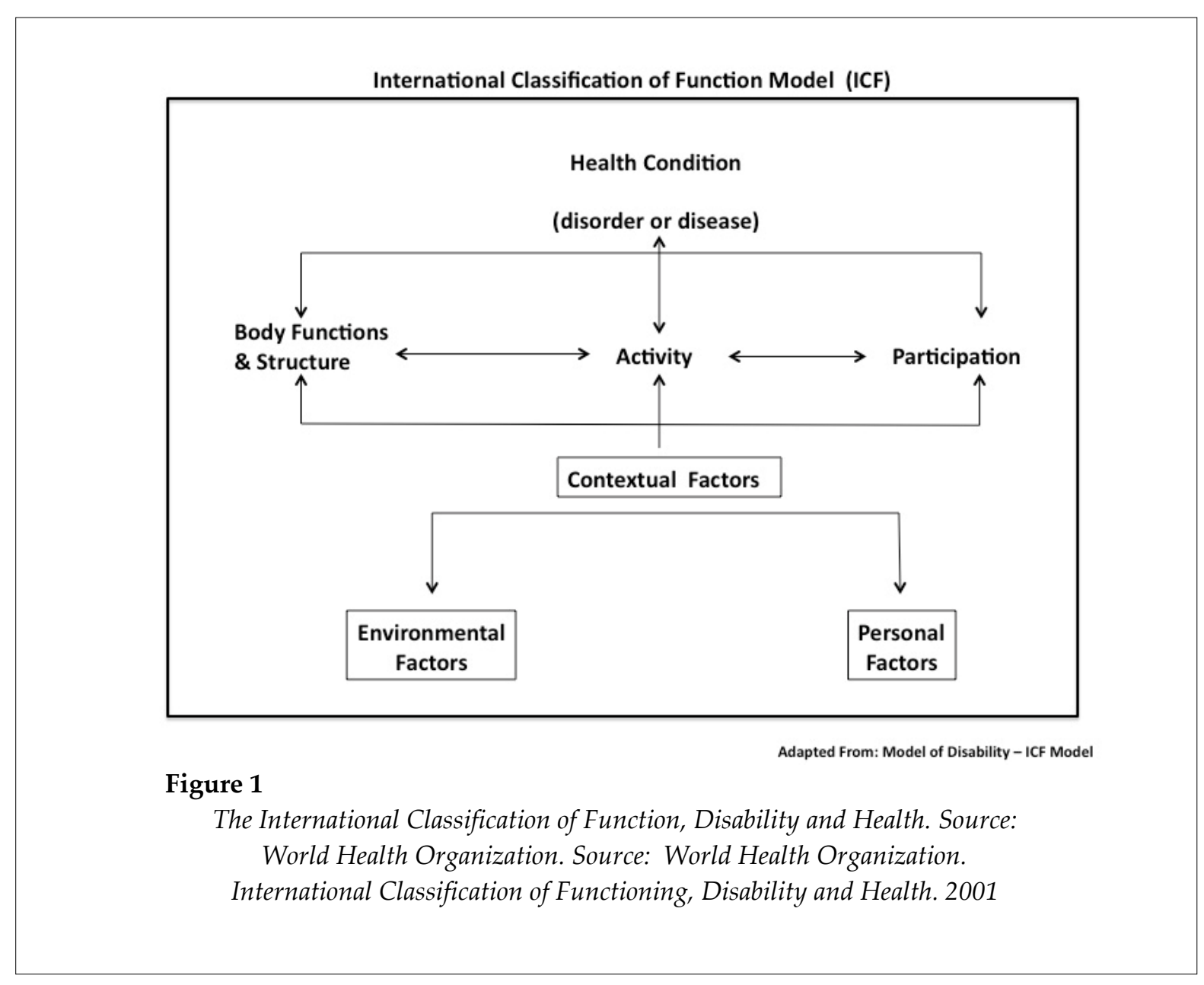




\section{HEALTH IMPROVEMENT CARD}

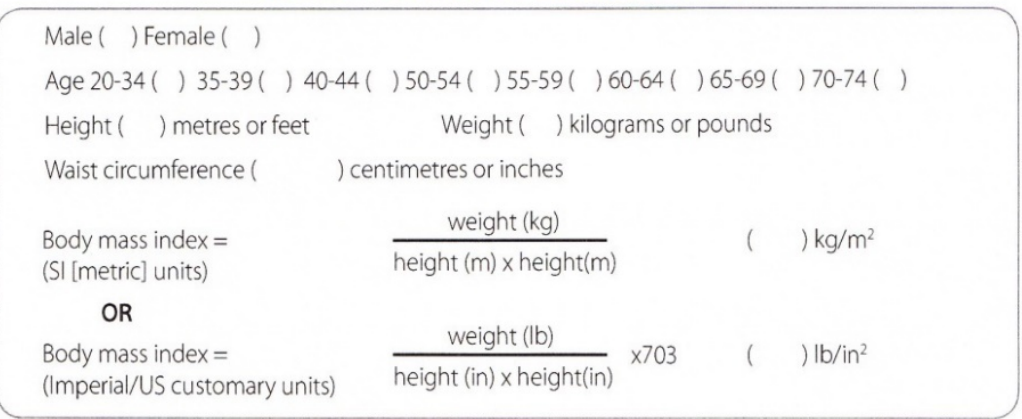

Biometrics scorecard

- helps you track measurable risk indicators which could over time damage your health, potentially leading to cancers, diabetes respiratory diseases, heart disease, mental health problems and oral diseases.

allows your health professional to help support you with information, advice, treatments (when indicated) and care enables you to improve your health through your own personalised action plan

\begin{tabular}{|c|c|c|c|}
\hline & GOAL & CAUTION & HIGH RISK \\
\hline BODY MASS INDEX & $18.5-24.9$ & $25-29.9$ & 30 or greater \\
\hline FASTING BLOOD SUGAR & $\begin{array}{l}\text { less than } \\
100 \mathrm{mg} / \mathrm{dL}\end{array}$ & $\begin{array}{l}100-125 \mathrm{mg} / \mathrm{dL} \\
\text { or treat to goal }\end{array}$ & $126 \mathrm{mg} / \mathrm{dL}$ or more \\
\hline CHOLESTEROL & $\begin{array}{l}\text { Less than } \\
200 \mathrm{mg} / \mathrm{dL} \\
\text { untreated }\end{array}$ & $\begin{array}{l}200-239 \mathrm{mg} / \mathrm{dL} \\
\text { or treat to goal }\end{array}$ & 240 or more $\mathrm{mg} / \mathrm{dL}$ \\
\hline BLOOD PRESSURE & $\begin{array}{l}\text { SBP less than } \\
120 \mathrm{mmHg} \\
\text { and DBP } \\
\text { less than } \\
80 \mathrm{mmHg}\end{array}$ & $\begin{array}{l}\text { SBP } 120-139 \\
\mathrm{mmHg} \text { and DBP } \\
80-89 \mathrm{mmHg}\end{array}$ & $\begin{array}{l}\text { SBP more than } \\
140 \mathrm{mmHg} \text { and } \\
\text { DBP more than } \\
90 \mathrm{mmHg}\end{array}$ \\
\hline
\end{tabular}

HEALTH IMPROVEMENT ACTION PLAN

\begin{tabular}{|c|c|c|}
\hline my commitment & \multirow{2}{*}{ my goal: } \\
\hline \multirow{2n}{\text{myaction}}{} & & target date: \\
\hline $\begin{array}{c}\text { health professional } \\
\text { action }\end{array}$ & & \\
\hline
\end{tabular}

For details, visit www.whpa.org

With the support of IFPMA

$$
\text { fip }=\text { (a) }
$$
(v) fip
IFPMA

\section{Figure 2a}

The Health Improvement Card. Source: World Health Professions Alliance 2014 Health (Part 1). 


\section{Lifestyle scorecard}

helps you understand how you can improve your health by changing your lifestyle allows your health professional to help you improve your health and well-being enables you to own and personalise your health improvement action plan

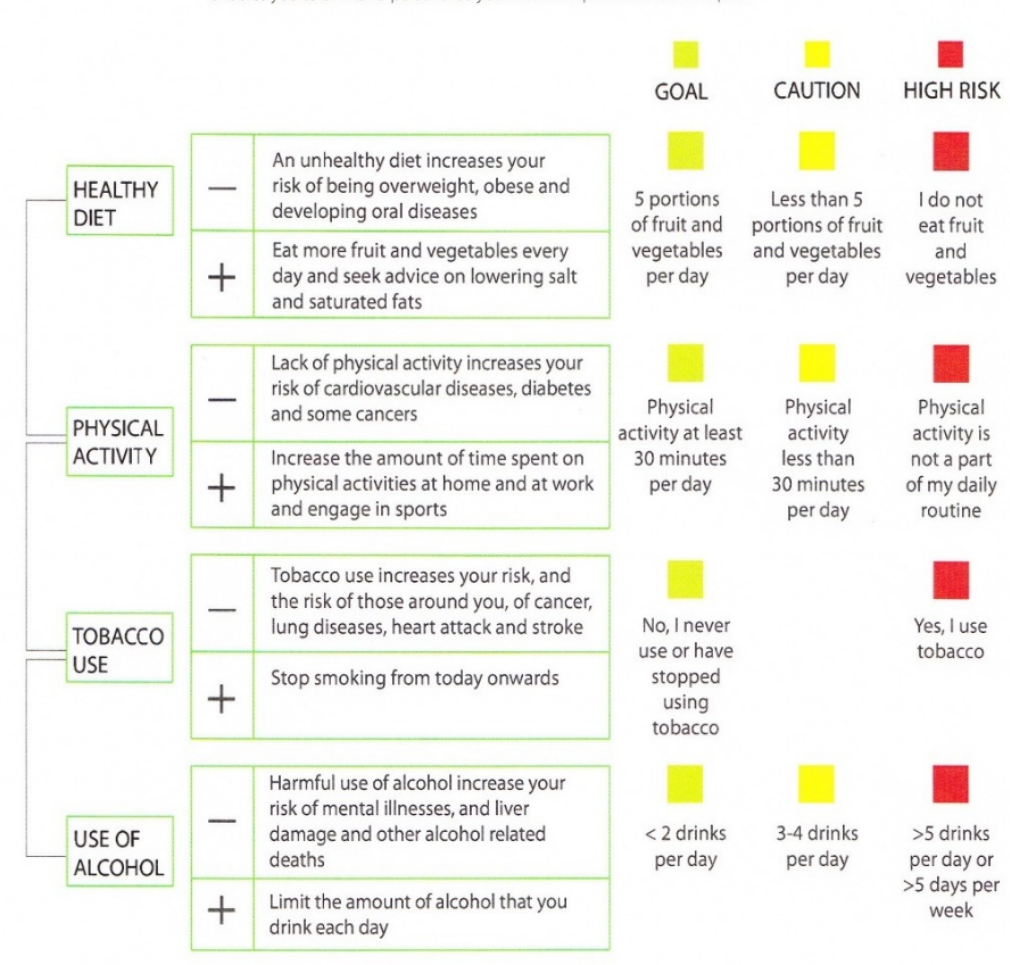

HEALTH IMPROVEMENT ACTION PLAN

\begin{tabular}{|c|c|c|}
\hline my commitment & & my goal: \\
\hline \multirow{2n}{\text{myaction}}{} & & target date: \\
\hline $\begin{array}{c}\text { health professional } \\
\text { action }\end{array}$ & & \\
\hline
\end{tabular}

For details, visit www.whpa.org

With the support of IFPMA

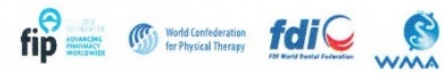

IFPMA

Figure $\mathbf{2 b}$

The Health Improvement Card. Source: World Health Professions Alliance 2014 Health (Part 2). 


\section{Optimal nutrition}

Optimal nutrition in fundamental to health yet little attention is given to the quality of foods people consume given the vast array of choices available to them. Daily food intake is not only important for energy, but for healing and repair of tissues, immunity and minimizing systemic chronic low-grade inflammation (Dean and Gormsen, 2012). Fat, sugar and salt often in the form of fast processed convenient food, that has become all too readily accessible, are a mainstay of the traditional western diet and increasing in non-western societies that tend to emulate western preferences and trends. Fat, especially saturated fat, sugar and salt have been associated with most of the leading causes of premature death and disability today (Harvard Medical School Special Health Report, 2016). Further, diets high in calorie-dense foods such as the standard western diet, are often at the expense of foods that comprise healthy Mediterraneantype diets (nutrient rich and generally low in calories), specifically, those rich in micro and macro nutrients found in whole grains, monounsaturated fats, and vegetables and fruit (Amor et al., 2017). These latter food groups are essential for maximum health, immune function, growth and repair, healing, physical functioning, disease prevention, and healthy aging. In addition, in a cohort of 54,762 women from the Nurses' Health Study, Hagan and colleagues (2016) reported greater adherence to the Alternative Healthy Eating Index (an index of a healthy diet) was associated with a lower incidence of physical functional impairment. These attributes of a healthy diet are no more important than for people with disabilities who require rehabilitation, thus warrant being a focus of attention. Food can be their medicine.

\section{Optimal body mass}

Overweight and obesity, a result of energy and nutrient imbalance, have become serious health issues in high-income countries and more apparent in low- and middle-income countries (World Health Organization. Global Strategy on Diet, Physical Activity, and Health, 2004). In the general population, the multisystem negative effects (physical and psychological) of adverse body composition especially abdominal fat have been well documented. However, excessive body mass is higher in persons with disabilities than those without, yet relatively little attention has been given to weight and body composition assessment in people with disabilities. Not only does increased body weight limit functional capacity but, in turn, it contributes to a host of other conditions that compound a person's overall health and wellbeing.

Optimal physical activity and structured exercise

Traditionally, rehabilitation has focused on movement. This can range from passive to active-assist in more compromised patients, such as those who are acutely ill including the intensive care unit, to active movement and exercise in patients recovering from a range of conditions including injury or working toward higher functional recovery when living with cancer, heart disease, stroke, Parkinson's syndrome, arthritis, gut conditions, and mental health conditions, to name a few.

Regular physical activity and structured exercise are well-documented to protect health and prevent disease, and improve function and treatment response when living with a chronic condition (Harvard Medical School Special Health Report, 2013, 2015). In fact, exercise is touted as the one prescription that lowers a person's risk for five major diseases with no side effects; an outcome not surpassed by any medication.

Athletes' training programs are uniquely tailored to their physiological capacities and the demands of their sports. In patients with chronic conditions, their activities of daily living and requirements for social participation also have unique characteristics that rehabilitation specialists need to identify and use as a basis for recommendations for physical activity and structured exercise programs, even though these are prescribed at a much lower intensity than for athletes. A high degree of competence in clinical reasoning is needed when working with individuals often living with one or more chronic conditions and on multiple medications. Important rehabilitation outcomes that are often overlooked are medication elimination or reduction with lifestyle recommendations including exercise, improved nutrition and weight loss, or avoidance of surgery or need for less invasive surgery.

The established guidelines for exercise are 150 minutes a week of moderately intense or 75 
minutes of intensive exercise (World Health Organization. Global Recommendations on Physical Activity for Health, 2010). Clearly, these levels are physiologically unrealistic for many individuals living with one or more chronic conditions. Thus, rehabilitation specialists need competencies in examining and assessing patients to prescribe exercise at a level that will provide them with most optimal conditioning that is possible. This prescription may need to change in accordance with changes in patients' status or medication regimens. Some conditions are hallmarked by periods of fatigue. In this case, daily fatigue profiles need to be factored into the exercise prescription for optimal responsiveness to the program, i.e., in the form of activity/exercise to rest periods.

Another consideration these days is sedentary behavior. Over the past decade, research has drawn attention to the negative effects of sedentary behavior in the general population and how such behavior has been implicated in several lifestyle-related NCDs (Ashe et al., 2009; Celis-Morales et al., 2012; Gennuso et al., 2013; Henson et al., 2013; Stamatakis et al., 2012). Sitting is an established NCD risk factor independent of physical activity and exercise levels (Thorp et al., 2010). That exercise alone even at the recommended levels for fitness does not offset the negative consequences of prolonged periods of sitting is an important finding. It suggests that breaking up periods of prolonged sitting, e.g., walking for 2 to 3 minutes every 30 to 60 minutes of sitting, is essential in conjunction with an exercise program.

\section{Manageable stress}

Over the past 30 years or so, more attention has been given to the psychological profiles of athletes. For maximal performance, such attention includes motivational aspects related to an athletic skill, mental well-being, anxiety, stress, depressive symptoms, and resilience including the capacity to manage disappointments in performance. For the person with a disability, his or her athletic 'event' is being able to perform activities of daily living, take care of the family, and participate socially. Living with a disability can compromise mental as well as physical health, specifically, can contribute to depression, anxiety and unmanageable stress (Harvard Medical School Special Health Report,
2011). Given the 21st century is hallmarked as the era of chronic vs. infectious conditions, a person's capacity to thrive living with one or more chronic conditions can make the difference between being confined to home, to working and participating effectively in the community. For this reason, the term resilience has become of interest in rehabilitation. Resilience is a strong indicator of health status. It is the capacity to effectively manage or bounce back from an adverse health event (Wells et al., 2012). Individuals with high levels of resilience are not necessarily less physically impaired than other individuals. Rather, they have developed psychological skills and strategies to accommodate their conditions and to maximize their function and well-being, despite living with one or more chronic conditions. The elements of resilience include dimensions of meaningfulness, perseverance, existential aloneness, and equanimity (Wagnild, 2009).

\section{Optimal sleep}

Western cultures are chronically sleep deprived (Coren, 2009). Stress, anxiety and depression are frequently associated with impaired sleep (Abrams, 2015). People with disabilities that are associated with musculoskeletal, neurological and cardiopulmonary signs and symptoms often have disrupted sleep requiring medication. In turn, impaired sleep limits a person's capacity to function well in the day and most certainly to respond maximally to a rehabilitation program. Chronic sleep deprivation is also associated with several non-communicable diseases including heart disease, high blood pressure, weight gain, and cancer (Harvard Medical School Special Health Report, 2013).

Sleep optimization was the secret to Sarah Hughes winning a gold medal at the 2002 Olympic Games (Maas and Robbins, 2010). She had had a prolonged period of no improvement in her workouts despite hours and hours devoted daily to workouts and practices. Dr. James Maas evaluated her performance and attributed lack of further improvement to sleep deprivation. He recommended an extra hour of sleep nightly so that Sarah started her practice rather than the usual 4:30 am. Within five months, Sarah showed increased performance and ultimately earned an Olympic gold medal, her dream (Maas and 
Robbins, 2010). Sarah's example above draws attention to the need to assess and evaluate the sleep, its quality and quantity, in patients in rehabilitation programs, and providing basic sleep recommendations as part of the rehabilitation program. Following response to these recommendations provides a means of improving functional capacity or explaining lack of response to standard elements of the rehabilitation program.

\section{The Health Improvement Card}

One tool that can be readily integrated into the practices of rehabilitation specialists is the Health Improvement Card (Figure 2a and 2b). This Card was developed by the World Health Professions Alliance (an alliance of the five leading established health professions in the world) in which the World Confederation for Physical Therapy had a pivotal role (World Health Professions Alliance 2014 Health Improvement Card 2014). The Card is two pages with four sections: patient information, physiologic/metabolic measures, lifestyle behaviors (smoking, diet, exercise, alcohol), and lastly, a section (two of them) to describe the patient's commitment and action plan, and the health professional's action plan to support the patient in effecting the action plan. The benefits of using this tool are several fold. First, it ensures that baseline data for a given patient during an episode of care is captured. This is essential for both the patient and the health professional. Second, it highlights to both individuals that healthy lifestyles are first and foremost in the health care agenda. Third, it externalizes sensitive issues about health behavior and minimizes the potential for 'blame and shame' of the patient in addressing smoking, alcohol consumption, nutrition, weight management, and physical activity. And fourth, the Card provides an entry point in the episode of care for targeted and tailored advice by the health professional in collaboration with the patient, with an inbuilt follow-up.

In addition, the practitioner should record the quality and quantity of the patient's sleep, and the patient's mental health (anxiety and depressive symptoms). Both sleep quality and quantity as well as mental health status influence existing health conditions and their course, as well as can be contributors and causes of these.
Implications for rehabilitation professions' practices, education and research

A health- and lifestyle-focused approach to rehabilitation has implications for the education of rehabilitation specialists and research as well as their practices. Improved management outcomes can be classified as proximal and distal. Lifestyle changes can improve proximal patient management outcomes with respect to reduced pain, improved biomechanics (e.g., through weight loss), and increased mobility and physical endurance, as well as faster recovery. In addition, long-term distal outcomes that reflect the impact of healthand lifestyle-focused rehabilitation include improved cost-effectiveness of faster recovery (less down time of the patient with respect to absenteeism from work and family time, less physician and rehabilitation specialist time, fewer drugs and potential for surgery, and if these are needed better response), and the benefit to the patient and society with respect to reducing prevalence of lifestyle-related NCDs over the long term. Two of three people will experience heart disease or cancer, and 9 of 10 will die from these conditions. With respect to research, the role of healthy living practices need to be elucidated regarding their confounding the improvement observed in conjunction with traditional rehabilitation programs. It is conceivable that not smoking, improved nutrition, weight loss, reduced sitting, improved sleep and reduced sleep, accounts for much of the variance in improvement of traditional rehabilitation programs that focus on physical activity and exercise. The extent of this improvement and the degree to which traditional exercise outcomes can be augmented warrants elucidation. Regardless, there is considerable evidence that in rehabilitation the goal needs to be 'health first', as it is for athletes.

\section{Conclusions}

Much consideration is given to improving the performance of athletes through healthy lifestyle practices combined with targeted and tailored training programs. Much less attention however has been given to maximizing the lifestyle practices of persons living with disabilities who are in need of rehabilitation to maximize their functional capacities, which 
traditionally has focused primarily on the exercise component. This is surprising given the well documented effects of adverse lifestyle practices on functional capacity and wellbeing and that these effects are likely accentuated in people with disabilities.

Specifically, the literature supports that healthy lifestyles are not only essential for health and wellbeing over the life cycle, but are critical in reducing the onset of lifestyle-related noncommunicable diseases, and in addition, minimizing their impact, and maximizing the benefits of traditional rehabilitation programs as well as biomedical interventions including pharmacological treatment and surgery. The
Health Improvement Card is one established tool that can be readily integrated into rehabilitation by health and fitness professionals with a view to assess non-communicable disease risk and related lifestyle practices, and to tailor lifestyle behavior change interventions within the rehabilitation program. In this way, responses to rehabilitation may be maximized and the rate of disease progression reduced. Further, other related morbidity may be offset or delayed in onset, and medication potentially reduced or eliminated. Such an approach is not only evidence-based, but highly cost-effective and ethical.

\section{References}

Abate M, Vanni D, Pantalone A, Salini V. Cigarette smoking and musculoskeletal disorders. Musc Lig Tend J, 2013; 3(2): 63-69

Abrams RM. Sleep deprivation. Obstet Gynecol Clin North Am, 2015; 42(3):493-506. doi: 10.1016/j.ogc.2015.05.013

A clinical practice guideline for treating tobacco use and dependence: 2008 Update. A US public health service report. Am J Prev Med, 2008; 35(2): 158-176

Ahluwalia IB, Mack KA, Murphy W, Mokdad AH, Bales VS. State-specific prevalence of selected chronic disease-related characteristics-Behavioral Risk Factor Surveillance System, 2001. MMWR Surveill Summ, 2003; 52(8): 1-80

Amor AJ, Serra-Mir M, Martínez-González MA, Corella D, Salas-Salvadó J, Fitó M, Estruch R, Serra-Majem L, Arós F, Babio N, Ros E, Ortega E; PREDIMED Investigators 2017 Prediction of cardiovascular disease by the Framingham-REGICOR equation in the high-risk PREDIMED Cohort: Impact of the Mediterranean diet across different risk strata. J Am Heart Assoc, 2017; 13: 6(3). pii: e004803. doi: 10.1161/JAHA.116.004803

Ashe MC, Miller WC, Eng JJ, Noreau L. Older adults, chronic disease and leisure-time physical activity. Gerontology, 2009; 55: 64-72

Blanchard CM, Courneya KS, Stein K. American Cancer Society's SCS-II. Cancer survivors' adherence to lifestyle behavior recommendations and associations with health-related quality of life: results from the American Cancer Society's SCS-II. J Clin Oncol, 2008; 26(13): 2198-2204

Buck D, Frosini F. 2012 Clustering of unhealthy behaviours over time: implications for policy and practice.

London, UK: The King's Fund.

http://www.kingsfund.org.uk/sites/files/kf/field/field_publication_file/clustering-of-unhealthybehaviours-over-time-aug-2012.pdf

Canada's Low Risk Alcohol Drinking Guidelines. http://www.ccsa.ca/Resource\%20Library/2012-CanadaLow-Risk-Alcohol-Drinking-Guidelines-Brochure-en.pdf

Celis-Morales CA, Perez-Bravo F, Ibanez L, Salas C, Bailey MES, Gill JMR. Objective vs. self-reported physical activity and sedentary time: effects of measurement method on relationships with risk biomarkers. PLoS ONE, 2012; 7(5): e36345

Coren S. Sleep health and its assessment and management in physical therapy practice: the evidence. Physiother Theory Prac., 2009; 25(5-6): 442-52 
Dean E. Physical therapy in the $21^{\text {st }}$ century (Part I): Toward practice informed by epidemiology and the crisis of lifestyle conditions. Physiother Theory Pract, 2009a; 25: 330-353

Dean E. Physical therapy in the 21 ${ }^{\text {st }}$ century (Part II): Evidence-based practice within the context of evidenceinformed practice. Physiother Theory Pract, 2009b; 25: 354-368

Dean E, Gormsen Hansen R. Prescribing optimal nutrition and physical activity as "first-line" interventions for best practice management of chronic low-grade inflammation associated with osteoarthritis: Evidence synthesis. Arthritis, 2012: 31: 560634. doi: 10.1155/2012/560634

Dean E, Söderlund A. What is the role of lifestyle behaviour change associated with non-communicable disease risk in managing musculoskeletal health conditions with special reference to chronic pain? BMC Musculoskel Disord, 2015; 13: 16-87. doi: 10.1186/s12891-015-0545-y

Ewing JA. Detecting alcoholism: The CAGE questionnaire. JAMA, 1984; 252: 1905-1907

Ford ES, Bergmann MM, Kröger J, Schienkiewitz A, Weikert C, Boeing H. Healthy living is the best revenge. Arch Int Med, 2009; 169: 1355-1362

Gennuso KP, Gangnon RE, Matthews CE, Thraen-Borowski KM, Colbert LH. Sedentary behavior, physical activity, and markers of health in older adults. Med Sci Sports Exerc, 2013; 45(8): 1493-1500

Hagan KA, Chiuve SE, Stampfer MJ, Katz JN, Grodstein F. Greater adherence to the alternative healthy eating index is associated with lower incidence of physical function impairment in the Nurses' Health Study. J Nutr, 2016; 146: 1341-1347

Harvard Medical School Special Health Report. Positive Psychology. Harvard Medical School Special Health Report. Harvard Medical School Press: Boston, MA. 2011

Harvard Medical School Special Health Report. Strength and Power Training. Harvard Medical School Special Health Report. Harvard Medical School Press: Boston, MA; 2013a

Harvard Medical School Special Health Report. Improving Sleep. Harvard Medical School Special Health Report. Harvard Medical School Press: Boston, MA; 2013b

Harvard Medical School Special Health Report. Starting to Exercise. Harvard Medical School Special Health Report. Harvard Medical School Press: Boston, MA; 2015

Harvard Medical School Special Health Report. Healthy Eating. Harvard Medical School Special Health Report. Harvard Medical School Press: Boston, MA; 2016

Henson J, Yates T, Biddle SJ, Edwardson CL, Khunti K, Wilmot EG, Gray LJ, Gorely T, Nimmo MA, Davies MJ. Associations of objectively measured sedentary behaviour and physical activity with markers of cardiometabolic health. Diabetologia, 2013; 56(5): 1012-1020

Hess AEM, Frohlich TC, Calio V. The heaviest-drinking countries in the world. https://www.usatoday.com/story/money/business/2014/05/17/heaviest-drinking-countries/9146227/

Klein D, Jeejeebhoy K, Tremblay A, Kallio M, Rheaume C, Humphries S, Royall D, Brauer P, Heyland D, Dhaliwal R, Mutch DM. The CHANGE program. Exercise intervention in primary care. Can Fam Phys, 2017; 63: 546-552

Maas JB, Robbins RS. Sleep for Success. Everything You Must Know About Sleep but Are Too Tired to Ask. Authorhouse: Bloomington, IN; 2010

McArdle WD, Katch FI, Katch VL. Exercise Physiology ( $8^{\text {th }}$ ed). Wolters Kluwer Health: Alphen aan den Rijn, The Netherlands; 2015

McGuire LC, Strine TW, Okoro CA, Ahluwalia IB, Ford ES. Healthy lifestyle behaviors among older U.S. adults with and without disabilities, Behavioral Risk Factor Surveillance System, 2003. Prev Chron Dis, 2007; 4(1): A09. https://www.cdc.gov/pcd/issues/2007/jan/06_0029.htm

Prentice WE. Principles of Athletic Training: A Competency-Based Approach (14th ed). McGraw-Hill:New York, NY; 2016

Rimmer JH, Vanderbom KA, Bandini LG, Drum CE, Luken K, Suarez-Balcazar Y, Graham ID. GRAIDs: a framework for closing the gap in the availability of health promotion programs and interventions for people with disabilities, Implement Sci, 2014; 14; 9: 100. doi: 10.1186/s13012-014-0100-5

Shiri R, Viikari-Juntura E, Varonen H, Heliövaara M. Prevalence and determinants of lateral and medial 
epicondylitis: a population study. Am J Epidemiol, 2006; 164(11): 1065-1074.

Stamatakis E, Hamer M, Mishra GD. Early adulthood television viewing and cardiometabolic risk profiles in early middle age: results from a population, prospective cohort study. Diabetologia, 2012; 55(2): 311320

Strine TW, Okoro CA, Chapman DP, Balluz LS, Ford ES, Ajani UA, Mokdad AH.Health-related quality of life and health risk behaviors among smokers. Am J Prev Med, 2005; 28(2): 182-187

Świątkiewicz G, Wieczorek $€$, Allamani A. What influences changes in alcoholic beverage consumption over time? Poland in the light of the European Union Amphora study. Subst Use Misuse, 2014; 49(12): 16011610. doi: $10.3109 / 10826084.2014 .914376$

Tsai J, Ford ES, Li C, Zhao G, Pearson WS, Balluz LS. Multiple healthy behaviors and optimal self-rated health: findings from the 2007 Behavioral Risk Factor Surveillance System Survey. Prev Med, 2010; 51(3-4): 268-274. doi: 10.1016/j.ypmed.2010.07.010

The Health Consequences of Smoking-50 Years of Progress: A Report of the Surgeon General. US Department of Health and Human Services, Centers for Disease Control and Prevention, Office on Smoking and Health. Rockville, MD, 2014.

https://www.ncbi.nlm.nih.gov/pubmed/24455788

The Surgeon General's Call to Action to Improve the Health and Wellness of Persons with Disabilities. Office of the Surgeon General (US); Office on Disability (US). Rockville (MD): Office of the Surgeon General (US); 2005. https://www.ncbi.nlm.nih.gov/books/NBK44667/pdf/Bookshelf_NBK44667.pdf

Thorp AA, Healy GN, Owen N, Salmon J, Ball K, Shaw JE, Zimmet PZ, Dunstan DW. Deleterious associations of sitting time and television viewing time with cardiometabolic risk biomarkers: Australian Diabetes, Obesity and Lifestyle (AusDiab) study 2004-2005. Diab Care, 2010; 33(2): 327-334

Wagnild G. A review of the Resilience Scale. J Nurs Meas, 2009; 17(2): 105-113

Wells M, Avers D, Brooks G. Resilience, physical performance measures, and self-perceived physical and mental health in older Catholic nuns. J Geriatr Phys Ther, 2012; 35(3): 126-131. doi: 10.1519/JPT.0b013e318237103f

World Health Organization. International Classification of Functioning, Disability and Health. 2001. http://www.sustainable-design.ie/arch/ICIDH-2PFDec-2000.pdf.

World Health Organization. Global Strategy on Diet, Physical Activity, and Health. 2004. http://www.who.int/dietphysicalactivity/strategy/eb11344/strategy_english_web.pdf

World Health Organization. Global Recommendations on Physical Activity for Health. Geneva: Switzerland; 2010

World Health Organization. Global Status Report on Alcohol and Health, 2014. Geneva: Switzerland. http://apps.who.int/iris/bitstream/10665/112736/1/9789240692763_eng.pdf

World Health Professions Alliance 2014 Health Improvement Card. Available from: http://www.ifpma.org/fileadmin/content/Publication/2011/ncd_Health-Improvement-Card_web-1.pdf

\section{Corresponding author:}

\section{Elizabeth Dean}

University of British Columbia

212, Friedman Building; 2177 Wesbrook Mall

Vancouver, British Columbia; Canada V6T 1 Z3

Phone: 1-604-822-7398

Fax: 1-604-822-1870

Email: elizabeth.dean@ubc.ca 